\title{
ПОБУДОВА МАТЕМАТИЧНОЇ МОДЕЛІ МЕХАНІЗМУ ПРИВОДУ НОЖА ПАПЕРОРІЗАЛЬНОЇ МАШИНИ БР-125
}

๑) С. Л. Панов, к.т.н., доцент, Р. В. Надточій, НТУУ “КПІ”, Київ, Україна

\author{
Разработан метод построения математической модели \\ шарнирно-рычажного механизма 3-го класса с применением \\ ПО «Maple». Рассмотрена методика дискретного расчета \\ кинематических характеристик звеньев в течении рабочего \\ цикла. Проведен кинематический расчет на примере \\ механизма привода ОРМ БР-125. Создана база для \\ проведения силового анализа.
}

Developed the method of constructing a mathematical model of 3rd class articulated lever mechanism using software "Maple". Considered the method of calculating the kinematic characteristics of discrete units during the working cycle. Performed a kinematic calculation on the example of the drive mechanism of papercutter BR-125. Created a framework for power analysis.

\section{Постановка проблеми}

3 точки зору теорії механізмів, кінематичний і силовий розрахунок механізмів третього порядку $є$ слабо дослідженим. Існуючі методи дослідження не $€$ універсальними і потребують побудови принципово різних алгоритмів розрахунків для різних механізмів.

\section{Аналіз попередніх досліджень}

У ході кінематичного аналізу плоских механізмів 3-го класу, здебільшого, використовується метод замкнутих векторних контурів [1]. Взявши за основу даний метод, Токмаковим Б. В. було побудовано математичну модель механізму приводу ОРМ БР-139. Недоліком такого підходу $€$ його недостатня універсальність, адже отримані мате- матичні залежності важко адаптувати для розрахунку інших механізмів.

\section{Мета роботи}

Провести повний кінематичний аналіз механізму приводу ножа БР-125. Визначити залежності швидкостей та прискорень основних точок механізму залежно від кута повороту вихідної ланки.

\section{Результати проведених досліджень}

Кінематичний аналіз проводиться у наступному порядку:

- побудова положень механізму протягом робочого циклу (полягає у визначенні координат основних точок залежно від положення вихідної ланки.

- визначення швидкостей основних точок. 
- визначення прискорень основних точок.

На рис. 1 представлено кінематичну схему приводу ножа, вихідними даними для розрахунку є довжини ланок:

$$
\begin{gathered}
\mathrm{O}_{1} \mathrm{~A}=96 \mathrm{~mm}, \mathrm{O}_{2} \mathrm{~B}=220 \mathrm{~mm}, \\
\mathrm{AB}=230 \mathrm{~mm}, \mathrm{BC}=812 \mathrm{Mm}, \\
\mathrm{O}_{3} \mathrm{D}=420 \mathrm{~mm}, \mathrm{O}_{4} \mathrm{E}=420 \mathrm{~mm}, \\
E D=1540 \mathrm{~mm}, \mathrm{DC}=197 \mathrm{~mm}, \\
E C=1723 \mathrm{~mm},
\end{gathered}
$$

та координати нерухомих точок:

$$
\mathrm{O}_{1}:(0 ; 0), \mathrm{O}_{2}:(0 ;-268) \text {, }
$$

$\mathrm{O}_{3}:(0 ; 1030), \mathrm{O}_{4}:(-1510 ; 1013)$,

де одиницею координат є 1 мм. Для визначення координат основних точок залежно від положення вихідної ланки скористаємось методом геометричних прив'язок [2], що полягає у «прив'язці» координат одної точки до координат іншої за допомогою геометричних законів. У нашому випадку аналітично ці прив'язки можна записати так:
$(\underline{B x}-A x)^{2}+(B y-A y)^{2}=A B^{2} ;$

$\left(\underline{B x}-\mathrm{O}_{2} \mathrm{x}\right)^{2}+\left(\underline{\mathrm{By}}-\mathrm{O}_{2} \mathrm{y}\right)^{2}=\mathrm{O}_{2} \mathrm{~B}^{2}$.

$(\underline{\mathrm{Cx}}-\mathrm{Bx})^{2}+(\underline{\mathrm{Cy}}-\mathrm{By})^{2}=\mathrm{BC}^{2}$;

$(\underline{\mathrm{Cx}}-\underline{\mathrm{Ex}})^{2}+(\underline{\mathrm{Cy}}-\underline{\mathrm{Ey}})^{2}=E C^{2}$;

$(\underline{\mathrm{Cx}}-\underline{\mathrm{Dx}})^{2}+(\underline{\mathrm{Cy}}-\underline{\mathrm{Dy}})^{2}=\mathrm{DC}^{2}$;

$\left(\underline{D x}-\mathrm{O}_{3} \mathrm{x}\right)^{2}+\left(\underline{\mathrm{Dy}}-\mathrm{O}_{3} \mathrm{y}\right)^{2}=\mathrm{O}_{3} \mathrm{D}^{2}$;

$\left(\underline{E x}-\mathrm{O}_{4} \mathrm{x}\right)^{2}+\left(\underline{\mathrm{Ey}}-\mathrm{O}_{4} \mathrm{y}\right)^{2}=\mathrm{O}_{4} \mathrm{E}^{2}$.

$(\underline{\mathrm{CX}}-\mathrm{Bx})^{2}+(\underline{\mathrm{Cy}}-\mathrm{By})^{2}=\mathrm{BC}^{2}$;

де кожна система рівнянь відповідає окремій групі Ассура [3], Ax, Аy, Вx, Ву... - координати точок по осі абсцис та ординат, підкреслені величини змінні (невідомі). Скориставшись пакетом математичного програмування «Maple», такі системи легко вирішуються і ми маємо змогу дізнатися положення усіх ланок в будь-який момент часу.

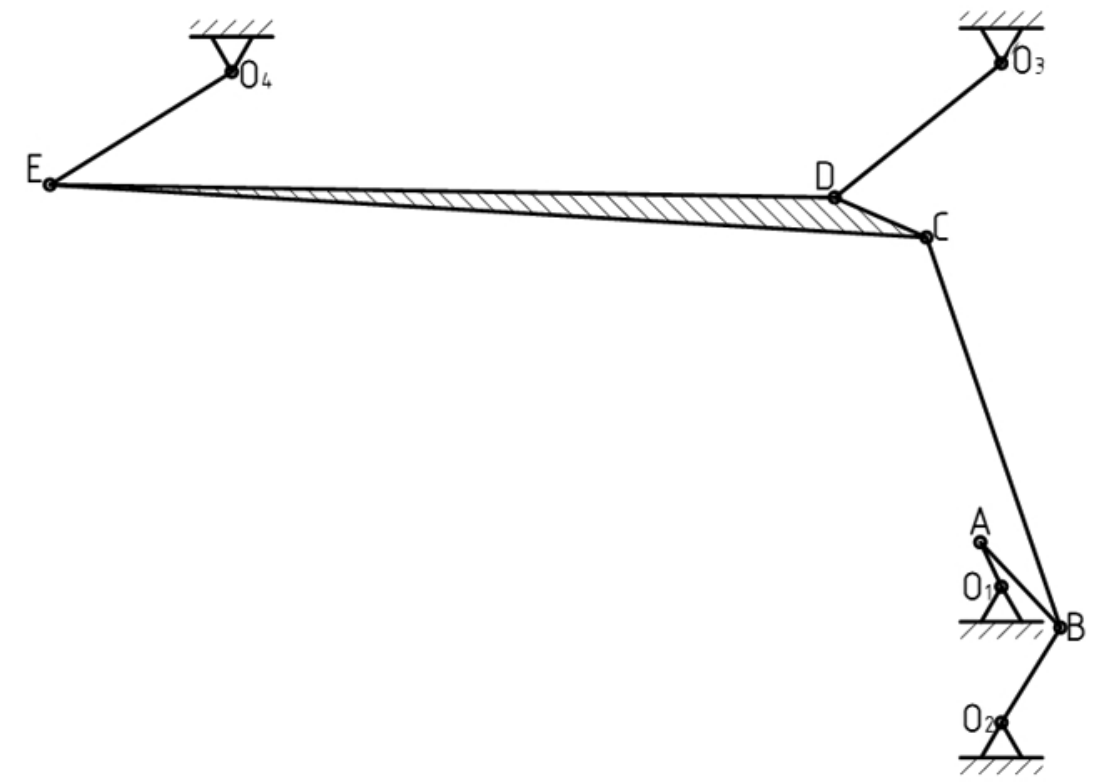

Рис. 1. Кінематична схема механізму приводу ножа БР-125 


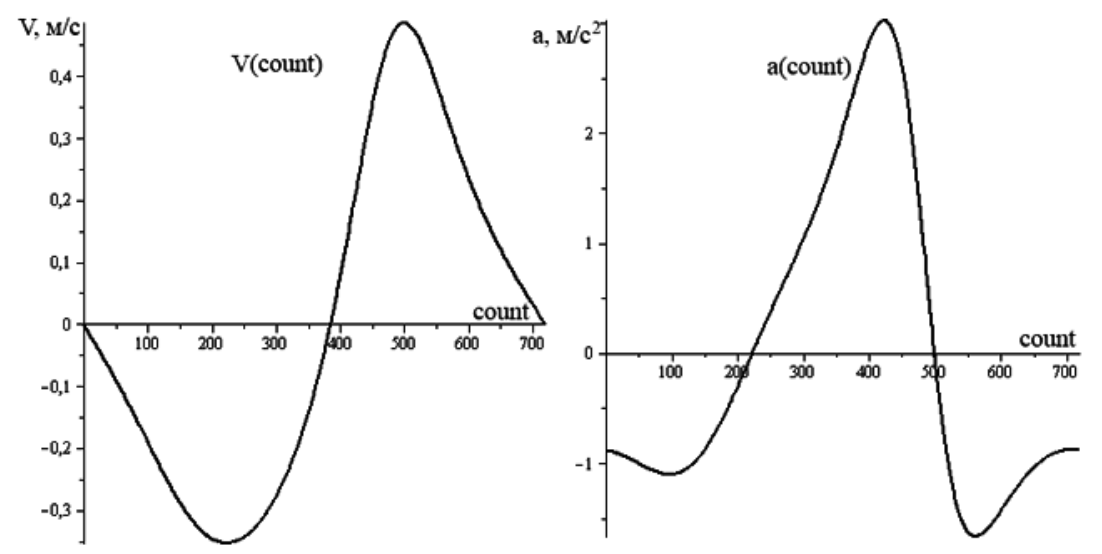

Рис. 2. Швидкість та прискорення ножа

Наступним етапом є визначення швидкостей та прискорень основних точок. Ці параметри можна визначити диференціюванням законів руху по осям. Але оскільки розраховано лише дискретні положення основних точок, то для диференціювання ще необхідно мати закон руху, записаний у вигляді неперервної функції. Оскільки підібрати функцію, що точно описувала б закон руху певної точки маючи лише дискретні координати, дуже складно (а іноді і неможливо), то доречно підбирати функції, що описували б закон руху лише у поточний момент. Для цього було використано метод інтерполяції поліномами Лагранджа по кожній осі, де у поточний момент для інтерполяції обираються координати точки у попередні два, та наступні два моменти і в поточний момент. Таким чином у кожен момент отримано можливість продиференціювати закон руху, беручи похідну від інтерполюючої функції у кожен момент.
Результати виконаних розрахунків необхідні для проведення силового аналізу окремих груп чи ланок та дають розуміння кінематики механізму. На рис. 2, a, б представлено вертикальні складові отриманих залежностей швидкості та прискорення центру леза ножа від номеру положення count початкової ланки $\mathrm{O}_{1} \mathrm{~A}$, відповідно. У проведеному дослідженні було розраховано 720 положень, тому різниця між двома послідовними положеннями початкової ланки складає $0,5^{\circ}$.

\section{Висновки}

В ході дослідження був здійснений повний кінематичний аналіз механізму приводу ножа одноножевої паперорізальної машини БР-125 аналітичним методом. Складність і новизна цих досліджень полягає у тому, що досліджуваний механізм є механізмом 3-го класу. Аналітичні методи дослідження таких механізмів в літературі описані недостатньо. Методи, що наведені в даній роботі, $€$ 
оригінальними і представлені у вигляді програми, написаної мовою програмування, прикладного пакету «Maple 13» із застосуванням його можливостей щодо математичних обрахунків. Очевидним ефектом від виконаної роботи є можливість швидко та точно розраховувати кінематичні параметри ме- ханізмів 2-го та 3-го класу з використанням ЕОМ. Точність розрахунків не обмежена.

Таким чином розроблена математична модель може бути корисна інженерам для розрахунку механізмів, що проектуються, студентам та аспірантам для теоретичного дослідження механізмів.

1. Тынкевич М. А. Численные методы анализа / М. А. Тынкевич. Кемерово, 2002. - 184 с. 2. Кочин Н. Е. Векторное исчисление и начала тензорного исчисления / Н. Е. Кочин. - М. : Наука, 1965. - 424 с. 3. Артоболевский И. И. Теория механизмов и машин : Учеб. для втузов. 4-е изд., перераб. и доп. - М. : Наука. Гл. ред. физ.-мат. лит., 1988. $640 \mathrm{c}$.

1. Tynkevich M. A. Chislennye metody analiza / M. A. Tynkevich. Kemerovo, 2002. - 184 s. 2. Kochin N. E. Vektornoe ischislenie i nachala tenzornogo ischislenija / N. E. Kochin. - M. : Nauka, 1965. - 424 s. 3. Artobolevskij I. I. Teorija mehanizmov i mashin : Ucheb. dlja vtuzov. - 4-e izd., pererab. i dop. - M. : Nauka. Gl. red. fiz.-mat. lit., 1988. - 640 s.

Рецензент - А. І. Іванко, к.т.н., доцент, НТУУ «КП।»

Надійшла до редакції 01.04.13 